\title{
Evaluation of the cost per patient per injection of botulinum toxin A in upper limb spasticity: comparison of two preparations in 19 countries
}

This article was published in the following Dove Press journal:

Medical Devices: Evidence and Research

19 November 2012

Number of times this article has been viewed

\section{Stéphane Roze' \\ Hannah Kurth ${ }^{2}$ \\ Barnaby Hunt ${ }^{3}$ \\ William Valentine ${ }^{3}$ \\ Rémi Marty'}

'HEVA, Lyon, France; ${ }^{2}$ Ipsen Pharma, Boulogne-Billancourt, France;

${ }^{3}$ Ossian Health Economics and

Communications, Basel, Switzerland
Correspondence: Stéphane Roze HEVA, 186 Avenue Thiers, 69006 Lyon, France

Tel +33472742560

Fax +334 72742525

Email sroze@hevaweb.com
Background: Botulinum toxin A injections are indicated for the management of movement disorders, including upper limb spasticity. The aim of this study was to compare the cost per patient per injection for two botulinum toxin A preparations in 19 countries.

Methods: Doses of botulinum toxin A are expressed in noninterchangeable units $(U)$, ie, Botox ${ }^{\circledR}$ in 100 Allergan units (100 U) and Dysport ${ }^{\circledR}$ in 500 Speywood units (500 U). Recommended dosages were derived from country-specific summaries of product characteristics or prescribing information. Cost analysis was based on official list prices and expressed in 2011 Euros. The cost per patient per injection was calculated using the recommended dosage in upper limb spasticity combined with price per vial in each country.

Results: For upper limb spasticity, the recommended dosage for Dysport in the summary of product characteristics is $1000 \mathrm{U}$ per patient, whereas for Botox the recommended dosage when recommendations were made is $300 \mathrm{U}$. Allowing for different prices per vial in each country, the cost per patient per injection for upper limb spasticity was less for Dysport than for Botox in 18 (95\%) of the 19 countries (mean 17\% less across countries). The difference was $20 \%$ or higher in nearly half (47\%) of the countries. Sensitivity analyses considering available "real-world" dosing showed consistent results, with Dysport being less costly than Botox in all 19 countries.

Conclusion: Considering costs per patient per injection based on analysis of recommended dosages in the summary of product characteristics, Dysport remains cheaper than Botox in most countries. Thus, when extrapolated to a national level, substantial savings could be realized by using Dysport in the treatment of upper limb spasticity.

Keywords: upper limb spasticity, stroke, botulinum toxin, Dysport ${ }^{\circledR}$, Botox ${ }^{\circledR}$

\section{Background}

Spasticity affects approximately 12 million patients worldwide, with around one third of stroke suffers and $60 \%$ of multiple sclerosis patients requiring treatment for the condition. ${ }^{1,2}$ Upper limb spasticity is the intermittent or sustained involuntary contraction of the muscles of the arm following a motor neuron lesion, resulting in abnormal posture of the arm, wrist, and hand. As well as causing substantial pain, these positions can make washing of the axilla, elbow crease, and hand difficult, leading to hygiene problems, which in turn can lead to skin breakdown, infections, and pressure sores. ${ }^{3}$ Furthermore, the sufferer's ability to carry out seemingly simple tasks, such as getting dressed or eating, is reduced to a level that often requires full time care. Thus, the disease impacts not only the patient, but also their immediate family. The most common cause of upper limb spasticity is stroke, accounting for $72 \%$ of cases. ${ }^{4}$ The economic consequences of spasticity following stroke are considerable, with a 
2003 study in Sweden finding that annual direct costs of care increased almost four-fold from approximately $\$ 22,000$ to $\$ 84,000$ in patients with spasticity sequelae. ${ }^{5}$ Optimizing treatment for patients with upper limb spasticity is likely to have an important impact on health care spending.

Botulinum toxin A therapy is the recommended pharmacological intervention, alongside physiotherapy and postural management programs, in the treatment of upper limb spasticity. ${ }^{1,2}$ When injected into selected muscles of the arm, the neurotoxin prevents release of acetylcholine at the neuromuscular junction, leading to a fall in the force of contraction. This allows the muscles to relax and normal posture to be resumed. Botulinum toxin A treatment has been associated with a significant increase in quality of life. ${ }^{6}$ Two preparations of botulinum toxin A are currently licensed for the treatment of upper limb spasticity, ie, Dysport (abobotulinumtoxinA; Ipsen Biopharm, Wrexham, UK) and Botox (onabotulinumtoxinA; Allergan, Inc, Irvine, CA). However, clinicians choosing which preparation to prescribe do not face an easy task. Manufacturing of the two preparations involves different processes, and different assays are used to measure the potency. ${ }^{7}$ This results in Dysport and Botox being described in terms of different, noninterchangeable units (U) of activity and, consequently, having different dosing regimens. The preparations are also supplied in differentsized vials. Dysport is provided in 500 Dysport unit (known as Speywood units in many countries) vials (500 U) while Botox is sold in 100 Allergan unit vials (100 U).

Therefore, the objective of this study was to compare the costs per patient per injection associated with treatment of upper limb spasticity using Dysport and Botox, in 19 countries where both products are approved and have similar reimbursement status, based on an analysis of recommended dosing, taking into account the different product units, dosing, and the vial acquisition costs of the two preparations.

\section{Materials and methods}

An injection was considered to be a single administration of the recommended dose of either preparation of botulinum toxin A. The cost per patient per injection was calculated for each of the two interventions by using the recommended dosing to determine the number of vials required, and then multiplying by the cost of a vial in each country. The costs of disposables, such as syringes, and medical professionals, were not taken into account because they were assumed to be the same for both preparations.

Recommended total doses of Dysport and Botox for treatment of upper limb spasticity were gathered from country-specific recommendations within the summary of product characteristics or prescribing information. The recommendations showed little variation between countries, with the recommended dose of Dysport being $1000 \mathrm{U}$ in all countries except Australia, where $750 \mathrm{U}$ was indicated. ${ }^{9}$ Country-specific recommendations for Botox were not available for all countries. However, where recommendations were made, they were $300 \mathrm{U}$, based on an analysis of recommended dosages for the most commonly injected muscles, ie, biceps brachii, flexor digitorum superficialis, flexor carpi radialis, flexor digitorum profundus, and flexor carpi ulnaris. ${ }^{9}$

Cost data were gathered from the official list prices for each preparation in all countries investigated, as detailed in Table 1. All costs were converted to Euros, using average exchange rates for the month of May $2011 .{ }^{8}$ The acquisition costs of both preparations showed heterogeneity across the 19 countries. ${ }^{9}$ In all cases, Dysport was more costly on a per vial basis, but fewer vials were required per patient per injection, based on recommended dosing.

\section{Results}

Treatment of upper limb spasticity was less costly, per patient per injection, for Dysport rather than Botox in 18 of the 19 countries investigated (Figure 1). The largest absolute

Table I Price per vial for Dysport ${ }^{\circledR} 500 \mathrm{U}$ and Botox ${ }^{\circledR} 100 \mathrm{U}$ in 19 countries

\begin{tabular}{lll}
\hline & $\begin{array}{l}\text { Dysport (€) } \\
\mathbf{5 0 0} \mathbf{U} \text { vial }\end{array}$ & $\begin{array}{l}\text { Botox (€) } \\
\text { I00 U vial }\end{array}$ \\
\hline Europe & & \\
Belgium (ex-factory price) & 222 & 167 \\
Estonia (ex-factory price) & 274 & 157 \\
France (ex-factory price) & 259 & 216 \\
Germany (ex-factory price) & 410 & 332 \\
Greece (ex-factory price) & 285 & 227 \\
Hungary (ex-factory price) & 259 & 241 \\
Italy (ex-factory price) & 175 & 129 \\
Netherlands (pharmacist purchase price) & 272 & 225 \\
Poland (ex-factory price) & 165 & 165 \\
Portugal (ex-factory price) & 197 & 163 \\
Spain (ex-factory price) & 173 & 159 \\
Sweden (ex-factory price) & 283 & 208 \\
Ukraine (ex-factory price) & 340 & 240 \\
United Kingdom (pharmacist & 177 & 159 \\
purchase price, I2.5\% margin) & & \\
United States & & \\
US (wholesale acquisition cost) & 499 & 369 \\
Rest of the world & & \\
Australia (price to customer) & 490 & 340 \\
Brazil (maximum price to consumer) & 797 & 765 \\
Korea (medical insurance price) & 233 & 225 \\
Russia (end-consumer price) & 475 & 370 \\
\hline Not Cost were convered & & \\
\hline
\end{tabular}

Note: Costs were converted into Euros based on average exchange rates in May $2011 .^{8}$ 
saving was seen in Brazil, where Dysport costs €701 less than Botox per patient per injection. The average saving across all countries was $€ 134$ per patient per injection, and the average saving across France, Germany, Italy, Spain, and the UK was $€ 109$ per patient per injection. Estonia was the only setting in which Dysport was more costly, with a $16 \%$ higher cost per patient per injection than Botox. In Brazil, Korea, and Poland, Dysport therapy was approximately one third cheaper per patient per injection than Botox, and across all 19 countries, an average of $17 \%$ could be saved through prescription of Dysport, rather than Botox, to patients with upper limb spasticity.

The doses used in this analysis were based on the dosing recommended in the summary of product characteristics. However, there is evidence that doses of Dysport used in clinical practice may be significantly lower than the published recommendations. An international noninterventional study found that the median dose of Dysport prescribed in upper limb spasticity was as low as $500 \mathrm{U}$ in some countries. ${ }^{4}$ A sensitivity analysis was performed to investigate the impact of prescription of lower doses of Dysport, assuming a $750 \mathrm{U}$ dose of Dysport (half-way between the lowest dose and the recommended dose), with the dose of Botox remaining at the recommended $300 \mathrm{U}$.

When dosing regimens of $750 \mathrm{U}$ of Dysport and $300 \mathrm{U}$ Botox were assumed, Dysport therapy was cost-saving per patient per injection in all countries (see Figure 2). The largest absolute difference was again seen in Brazil, but the difference in cost per patient per injection increased to $€ 1100$. In Estonia, the only country in which Botox therapy was less costly per patient per injection when recommended doses were assumed, Dysport was cost-saving, with an absolute difference of $€ 60$ per patient per injection. In Poland, Korea, Brazil, and Hungary, the cost per patient per injection with Dysport was approximately half the cost of Botox therapy. On average, across all countries, the cost per patient per injection for patients with upper limb spasticity was 38\% lower for Dysport than Botox when doses of $750 \mathrm{U}$ and $300 \mathrm{U}$, respectively, were assumed.

\section{Discussion}

In nearly all (18 of 19) countries analyzed in this study, Dysport therapy for upper limb spasticity was less costly than Botox treatment, on a cost per patient per injection basis. At a national level, these cost differences could result in substantial savings in health care spending. Stroke, the most common cause of upper limb spasticity, typically occurs at approximately 70 years of age, ${ }^{10}$ and patients with subsequent spasticity will require chronic treatment at 12-16-week intervals. ${ }^{1}$ Assuming an average patient receives 3.7 treatments per year, average annual savings of $€ 15$ to $€ 2591$ per patient could be made through prescription of Dysport rather than Botox. In settings such as Brazil, Korea, and Poland, where Dysport was approximately one third less costly than Botox per patient per injection, cost savings ranged from $€ 596$ to $€ 2591$ per

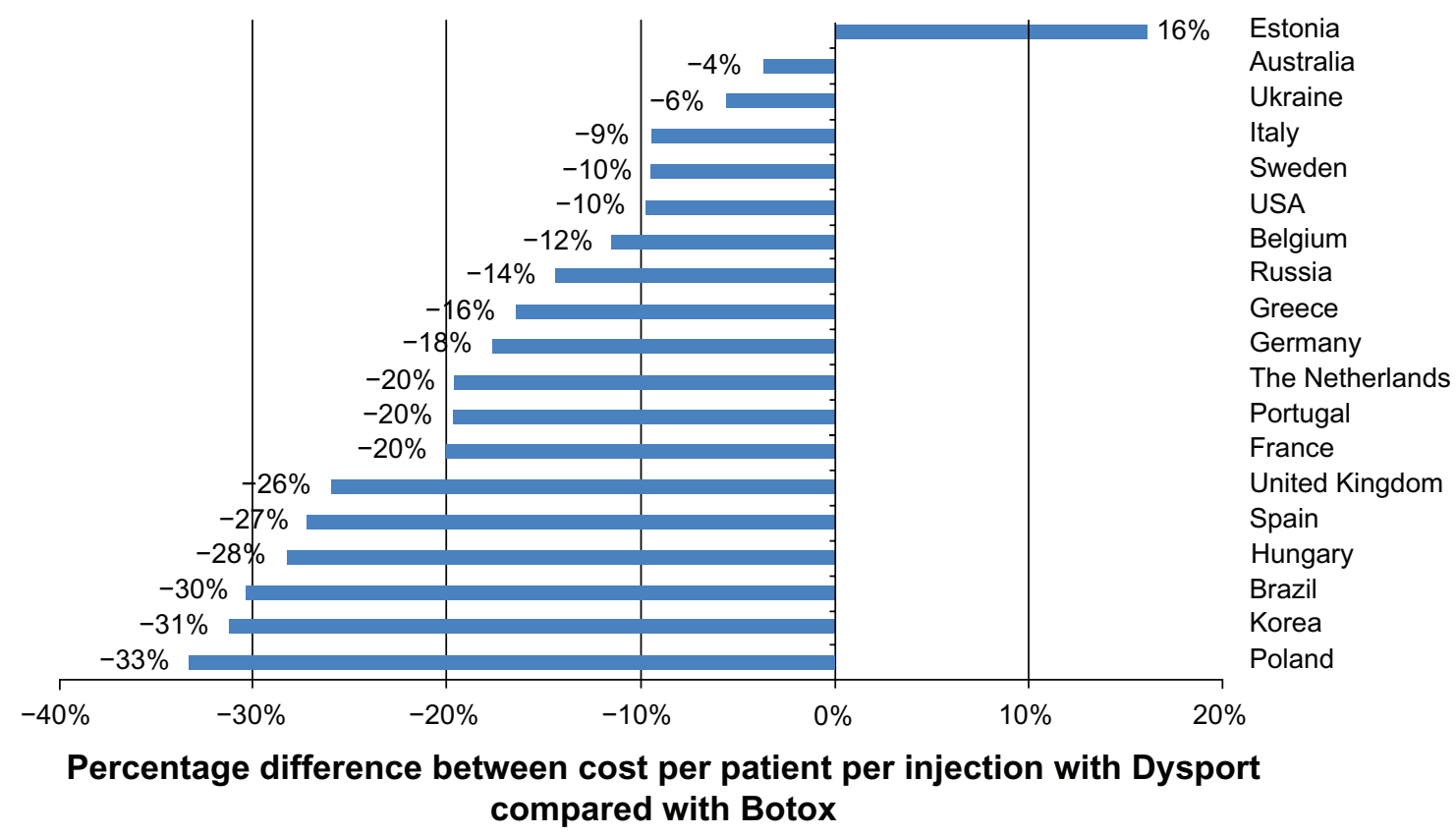

Figure I Cost per patient per injection with Dysport ${ }^{\circledR}$ compared with Botox $^{\circledR}$, based on recommended dosing. 


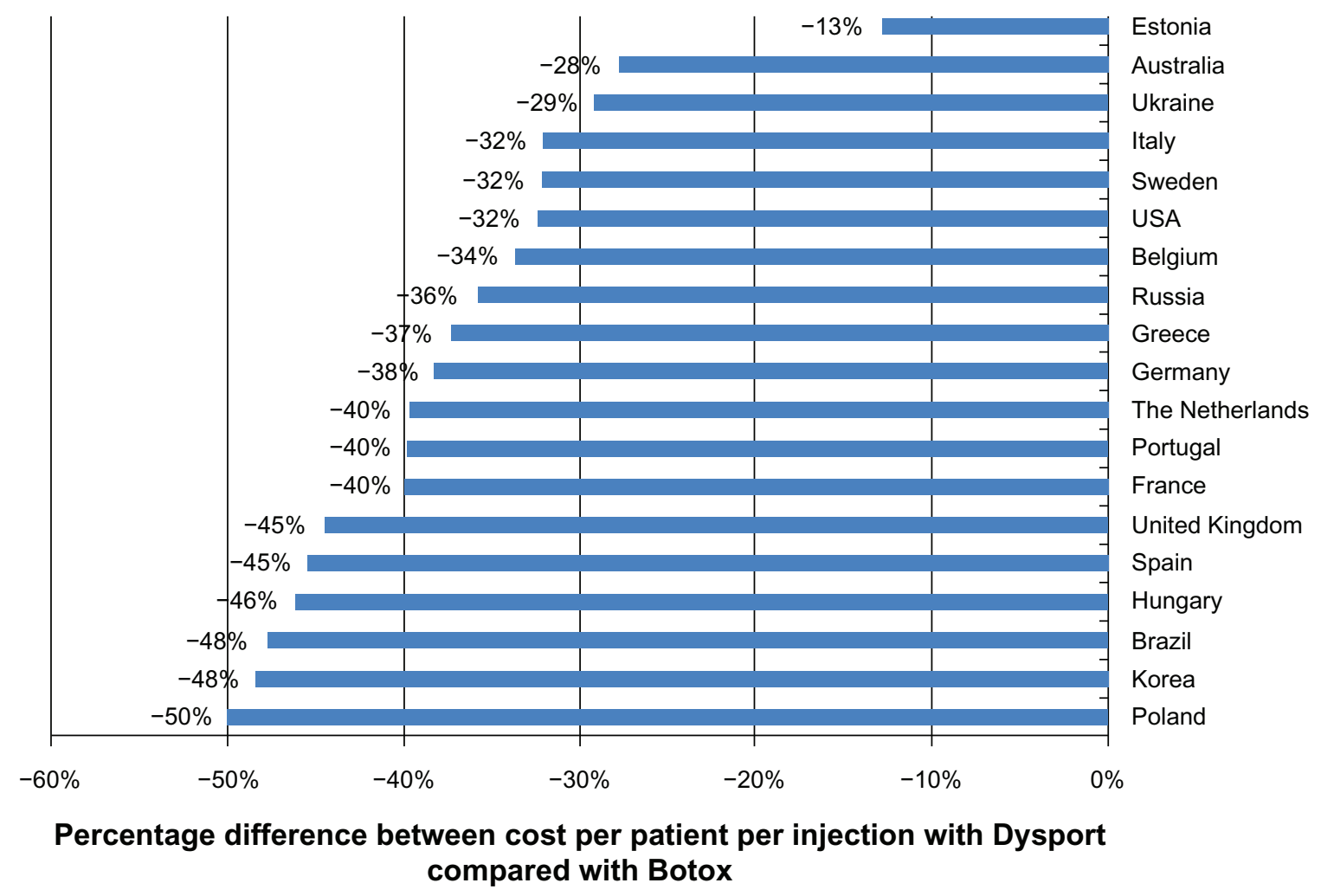

Figure 2 Cost per patient per injection with Dysport ${ }^{\circledast}$ compared with Botox $^{\circledast}$, based on an assumed dosage of $750 \cup$ Dysport and $300 \cup$ Botox.

patient per year. Estonia was the only study country in which Dysport was more costly than Botox. The cost difference between the two therapies was estimated to be $€ 283$ per patient per year (assuming 3.7 treatments per year). In all other countries, more patients could be treated with botulinum toxin A given a particular health care budget by using Dysport versus Botox.

This study was carried out using an analysis of recommended dosing from the summary of product characteristics and product information to calculate the cost of treating upper limb spasticity. However, in real-world clinical practice, the recommended dose may not always be prescribed, because the appropriate dose depends on severity of spasticity and muscle size. A survey of clinicians in France, Germany, Greece, Sweden, and the UK by STETHOS International Marketing Research found that the mean dose of Dysport prescribed, as reported by physicians, was lower than the recommended dose in all countries. The doses ranged from $508 \mathrm{U}$ in France to $773 \mathrm{U}$ in Germany. Furthermore, an analysis of interim data from a recent noninterventional study of 974 patients with upper limb spasticity in 31 countries found that the doses of Dysport used in clinical practice are consistently lower than the recommendations in the summary of product characteristics. ${ }^{4}$ The median prescribed dose across all countries was $700 \mathrm{U}$, but in Asian countries the median dose was $500 \mathrm{U}$. This deviation from the recommended Dysport dose of $1000 \mathrm{U}$ may lead to substantial cost-savings in real-life clinical practice, as shown by the sensitivity analysis in this investigation, where a conservative clinical practice dose of $750 \mathrm{U}$ of Dysport was assumed. A potential limitation of this sensitivity analysis is that it assumed that there was no wastage. This may be possible in clinics that care for a large number of stroke patients with upper limb spasticity sequelae (ie, three $500 \mathrm{U}$ vials are used to administer $750 \mathrm{U}$ each to two patients, ie, no wastage, versus the use of two $500 \mathrm{U}$ vials per patient, resulting in $250 \mathrm{U}$ of product wasted per patient). Also, in some countries $300 \mathrm{U}$ vials of Dysport are now available, which could reduce wastage through a more adapted dose. There is also evidence that Botox dosing in a clinical setting may be lower than the recommended dosing. ${ }^{11}$ Further analysis of costs per patient per injection based on data from real-world clinical practice is needed to investigate further the likely potential savings possible for health care payers based on botulinum toxin A usage in clinical settings.

It should also be noted that the actual drug acquisition costs may be less than the official list price. As such, and combined with deviations in real-world dosing practice versus 
recommended dosages as found in the summaries of product characteristics, the real costs per patient per injection may be different than those calculated in the present study. However, in the absence of gross differences in price discounts for the two drugs, the relative differences in real-world costs per patient per injection for Dysport versus Botox should still reflect those found in the present study for a given patient etiology, severity, and presentation.

The present investigation found that, in the majority of countries, treatment of upper limb spasticity using Dysport is less costly than Botox, based on recommended dosing regimens. There is also evidence that doses of Dysport used in real-world clinical practice may be lower than the recommended prescriptions, resulting in a lower overall treatment cost for Dysport. Due to the chronic nature of treatment and the significant prevalence of upper limb spasticity following stroke worldwide, the impact of any cost savings at a national level may be substantial.

\section{Disclosure}

This study was supported by an unrestricted grant from Ipsen Pharma.

\section{References}

1. Royal College of Physicians, British Society of Rehabilitation Medicine, Chartered Society of Physiotherapy, Association of Chartered Physiotherapists Interested in Neurology. Spasticity in adults: management using botulinum toxin. National guidelines. London, UK: Royal College of Physicians; 2009.

2. Gallichio JE. Pharmacologic management of spasticity following stroke. Phys Ther. 2004;84(10):973-981.
3. Shaw L, Rodgers H, Price C, et al. BoTULS: a multicentre randomised controlled trial to evaluate the clinical effectiveness and cost-effectiveness of treating upper limb spasticity due to stroke with botulinum toxin type A. Health Technol Assess. 2010;14(26):1-113.

4. Bakheit AM, Zakine B, Maisonobe P, et al. The profile of patients and current practice of treatment of upper limb muscle spasticity with botulinum toxin type A: an international survey. Int J Rehabil Res. 2010;33(3):199-204.

5. Lundström E, Smits A, Borg J, et al. Four-fold increase in direct costs of stroke survivors with spasticity compared with stroke survivors without spasticity: the first year after the event. Stroke. 2010;41(2):319-324.

6. Elovic EP, Brashear A, Kaelin D, et al. Repeated treatments with botulinum toxin type a produce sustained decreases in the limitations associated with focal upper-limb poststroke spasticity for caregivers and patients. Arch Phys Med Rehabil. 2008;89(5):799-806.

7. Keam SJ, Muir VJ, Deeks ED. Botulinum toxin A (Dysport $\left.{ }^{\circledR}\right)$ : in dystonias and focal spasticity. Drugs. 2011;71(8):1043-1058.

8. Oanda ${ }^{\circledR}$. Historical exchange rates for the month of May 2011 Available from: http://www.oanda.com/currency/historical-rates/. Accessed September 13, 2012.

9. Roze S, Marty R, Kurth H, et al. Economic analysis of cost per episode of care for arm spasticity and cervical dystonia: comparison of two botulinum toxin A preparations in 20 countries. Presented at the International Society for Pharmacoeconomics and Outcomes Research 14th Annual European Congress, Madrid, Spain, November 5-8, 2011.

10. Shiue I. Age of onset for stroke delayed in the 21st century: what is next? Clin Neurol Neurosurg. 2011;113(9):725-726.

11. Slawek J, Bogucki A, Reclawowicz D. Botulinum toxin type A for upper limb spasticity following stroke: an open-label study with individualised, flexible injection regimens. Neurol Sci. 2005;26(1):32-39.
Medical Devices: Evidence and Research

\section{Publish your work in this journal}

Medical Devices: Evidence and Research is an international, peerreviewed, open access journal that focuses on the evidence, technology, research, and expert opinion supporting the use and application of medical devices in the diagnosis, treatment and management of clinical conditions and physiological processes. The identification of novel

\section{Dovepress}

devices and optimal use of existing devices which will lead to improved clinical outcomes and more effective patient management and safety is a key feature. The manuscript management system is completely online and includes a quick and fair peer-review system. Visit http://www. dovepress.com/testimonials.php to read real quotes from authors. 